University of Rhode Island

DigitalCommons@URI

Open Access Master's Theses

2020

\title{
“THE 'REAL COST’ OF CAMPAIGNS: ENDS CAMPAIGN EFFECTIVENESS IN TERMS OF AWARENESS AND CONTENT"
}

Brandon Donohue

University of Rhode Island, brandondonohoe96@gmail.com

Follow this and additional works at: https://digitalcommons.uri.edu/theses

\section{Recommended Citation}

Donohue, Brandon, "'THE 'REAL COST' OF CAMPAIGNS: ENDS CAMPAIGN EFFECTIVENESS IN TERMS OF AWARENESS AND CONTENT"'m (2020). Open Access Master's Theses. Paper 1919.

https://digitalcommons.uri.edu/theses/1919

This Thesis is brought to you for free and open access by DigitalCommons@URI. It has been accepted for inclusion in Open Access Master's Theses by an authorized administrator of DigitalCommons@URI. For more information, please contact digitalcommons-group@uri.edu. 
“THE ‘REAL COST’ OF CAMPAIGNS: ENDS CAMPAIGN EFFECTIVENESS IN TERMS OF AWARENESS AND CONTENT"

BY

BRANDON DONOHOE

A THESIS SUBMITTED IN PARTIAL FULFILLMENT OF THE

REQUIREMENTS FOR THE DEGREE OF

MASTER OF ARTS

IN

COMMUNICATION STUDIES

UNIVERSITY OF RHODE ISLAND

2020 


\title{
MASTER OF ARTS IN COMMUNICATION STUDIES THESIS
}

$\mathrm{OF}$

\section{BRANDON DONOHOE}

\author{
APPROVED: \\ Thesis Committee: \\ Major Professor Geoff Leatham \\ Yinjiao Ye \\ Daniel Sheinin \\ Mary Moen \\ Brenton DeBoef \\ DEAN OF THE GRADUATE SCHOOL
}

UNIVERSITY OF RHODE ISLAND

2020 


\begin{abstract}
Over the past few years, the use of electronic cigarettes and other vaping related products has spiked. This has quickly become an epidemic amongst the younger generations. These people did not smoke cigarettes before but are now addicted to nicotine. In an attempt to fight off the companies that are marketing these devices to teens and young adults, various anti-vaping campaigns have been launched. Two of the most notable and prevalent campaigns are the FDA's "The Real Cost" and the Truth Initiative's "Truth". Using previously tested methods, this study compares and attempts to account for the short-term effectiveness, or lack thereof, of these two campaigns. Campaign awareness, motivation and message content are the key measures used in this study. The content is analyzed using the Elaboration Likelihood Model to measure the identification of central and peripheral cues. Three graduate students ran a content analysis on videos produced by these organizations and 138 students were surveyed regarding their awareness of the campaigns, vaping interest/motivation, and their perceptions of a video advertisement. Students were more likely to identify the central cues, but the peripheral predictors were the only ones found to be significant. Motivation is also a significant predictor of PSA effectiveness. It is recommended that the campaigns use better audience targeting and segmentation to identify individuals with a high motivation, or interest in vaping. Emotional Appeal is the most significant predictor of video effectiveness.
\end{abstract}




\section{ACKNOWLEDGMENTS}

I would like to thank many people for this project. The last semester of my graduate school experience has been chaotic with all that is going on in the world and without my committee none of this would have been possible. Dr. Leatham has had my back throughout this whole process and Dr. Ye worked tirelessly to ensure my graduation. I would also like to thank all of the graduate student instructors and professors that allowed me to survey their students. I have learned a lot through this process, and I am grateful for the perspective that Dr. Sheinin brought to the project. This study would not have been as well rounded as it is without your insight. 


\section{TABLE OF CONTENTS}

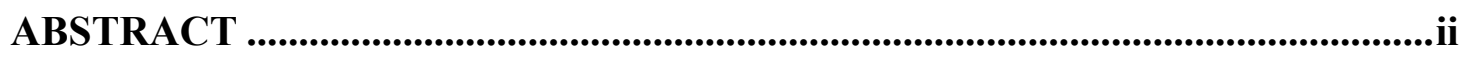

ACKNOWLEDGMENTS................................................................................................iii

TABLE OF CONTENTS .....................................................................................iv

LIST OF TABLES............................................................................................................

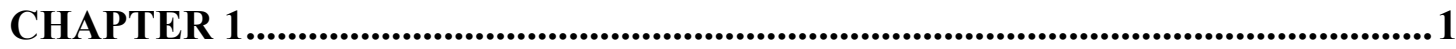

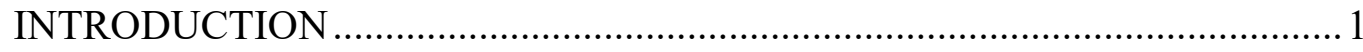

CHAPTER 2........................................................................................................................6

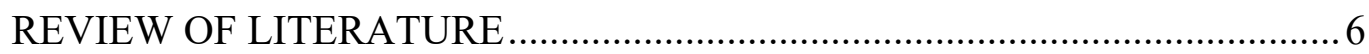

CHAPTER 3........................................................................................................................ 16

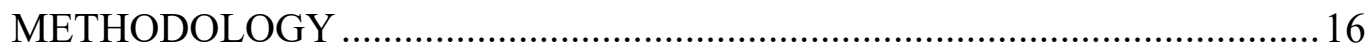

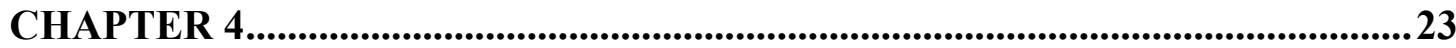

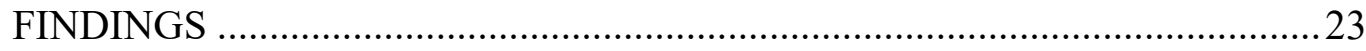

CHAPTER 5

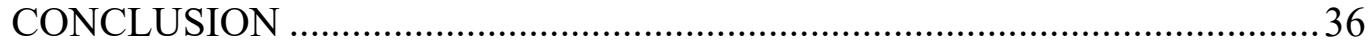

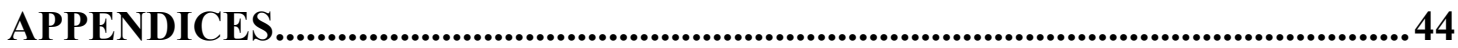

BIBLIOGRAPHY .............................................................................................................52 


\section{LIST OF TABLES}

TABLE

PAGE

Table 1. Coder and participant richness scores......................................................23

Table 2. Coder and participant deviation ............................................................. 24

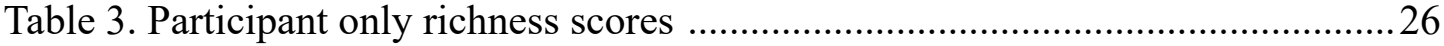

Table 4. Argument richness and message appeal comparison ..................................29

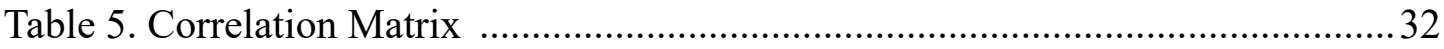

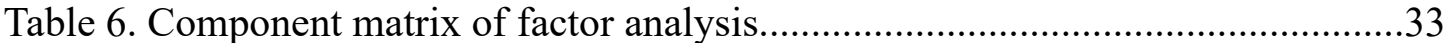




\section{CHAPTER 1}

\section{INTRODUCTION}

Use of electronic cigarettes and other Electronic Nicotine Delivery Systems (ENDS) have become an epidemic amongst young people yet knowledge of the health consequences is limited at best (Centers for Disease Control, 2019). Electronic cigarettes are defined by the National Cancer Institute as devices that recreate the experience of smoking a cigarette without the use of tobacco, although they often contain varying amounts of nicotine (National Cancer Institute, n.d.).

As new research comes out, we are learning that these devices are much more harmful than originally thought. Recently, numerous cases of serious lung illness have been linked to teen vaping. In addition, the FDA reports that "over 3.6 million youths used e-cigs, making them the most commonly used tobacco product" (Youth Tobacco Use: Results from the National Youth Tobacco Survey, 2019). Recent reports have noted drastic increases in adolescent's use of e-cigarettes. Roughly 1.3 million more teenagers reported using them between 2017 and 2018 which was a 10 percent increase (Farzal, Perry, Yarbrough, \& Kimple 2019). Notably, the CDC reported that, in the same time frame, all other forms of tobacco use in teens decreased (Centers for Disease Control and Prevention, 2020b).

This is in part due to advertising that was specifically created for and directed at teens and young adults. Social media was a primary channel for e-cigarette advertisements. A report by the National Institute of Health estimated that over 78 percent of high schoolers 
and middle scholars were exposed to e-cigarette advertising, with exposure increasing every year (Marynak, Gentzke, Wang, Neff, \& King, 2018). Additionally, exposure to ecigarette commercials has been shown to be positively related to use, meaning that students between grades 6 and 12 are more likely to use electronic cigarettes if they see ecigarette ads at least “sometimes” (Singh, Agaku, Arrazola, Marynak, Neff, Rolle, \& King, 2016). A growing trend of youth exposure to e-cigarette campaigns and evidence that exposure leads to use means that studying anti-e-cigarette campaigns has never been more important.

According to an article by Janice Selekman, a professor in the School of Nursing at the University of Delaware, the combination of adolescents being told that "vaping is cool", as well as the seamless ability to hide the small devices and their smoke, are contributors to the increase in their popularity among teens (Selekman, 2019). On top of that, vaping is incredibly addictive and "teens have also been shown to be more susceptible to addiction" (Jones \& Salzman, 2020). Once addicted to nicotine, it is far more likely that an individual will start smoking combustible, or traditional, cigarettes. The National Institute of Health states that "adolescents who use e-cigarettes are 3.6 times more likely to report using combustible cigarettes later in life" (Jones \& Salzman, 2020). Considering this fact, the health risks of vaping as a teen are magnified. Not only are the long-term effects of vaping and e-cigarette use unknown, but increased chances of smoking combustible cigarettes can be devastating to lung health.

Late in 2019, several adolescents fell ill with a mysterious illness related to vaping that later became referred to as e-cigarette, or vaping, product use-associated lung injury (EVALI). Chemicals found in both THC and non-THC (e-cigarettes) vaping devices were 
identified as contributors to EVALI. A total of 2,807 hospitalized cases of EVALI were reported by the CDC including 68 deaths (Centers for Disease Control, 2020a). In addition to susceptibility to lung illnesses such as EVALI, Stanford Medicine has also reported that vaping and e-cigarette use can increase risk of COVID-19 contraction in teenagers and young adults (Gaiha, Cheng, \& Halpern-Felsher, 2020). As of October 9, 2020, the United States has had 7.6 million total cases of COVID-19 and over 200,000 total deaths. The recent study out of Stanford Medicine stated that e-cigarette use was positively correlated with "COVID-19 testing and positive diagnosis" (Gaiha, Cheng, \& Halpern-Felsher, 2020). Although this study did not inquire about the severity of symptoms in relation to e-cigarette users and non-users, it does contribute to the growing importance of anti-vaping campaigns.

For these reasons, it is particularly important that we analyze the campaigns that intend to prevent young people from picking up this potentially dangerous habit. Up to this point, no publicly published study has directly applied the concepts of market penetration and message content to analyze the FDA's "Real Cost" ENDS campaign or the Truth Initiative's “The Truth" campaign. Past research has long pointed to the importance of both of these factors in the effectiveness of a health campaign (Anker, Feeley, McCracken, \& Lagoe, 2016; Dobbinson, Wakefield, Jamsen, Herd, Spittal, Lipscomb, \& Hill, 2008; Palmgreen \& Donohew, 2006).

Studying the effectiveness and awareness of mass media public health campaigns is not a new phenomenon. Since the birth of these campaigns, it has been crucial to learn about their success. It has also been important for researchers to distinguish between recalling the campaign and recalling a message from the campaign (Peetz-Schou, 1997). 
Past research has implicated that it is more effective to ask participants whether they have seen or been exposed to a campaign in multiple instances and get an aggregate score for best results (Peetz-Schou, 1997). This is important to the mental pathways outlined in the Elaboration Likelihood Model. The model insists on being able to process information as it is presented in one of two ways; centrally or peripherally (Petty \& Cacioppo, 1986). In order to process this information through either of the aforementioned pathways, one must first be exposed to the information in a way that encourages processing to take place. This highlights the importance of campaign exposure. It is a crucial factor of any public health campaign that must be incorporated into any study of campaign effectiveness.

Numerous studies have reported that mass media public health campaigns can be effective in changing health behaviors in a target audience (Anker, Feeley, McCracken, \& Lagoe, 2016; Palmgreen, Donohew, Lorch, Hoyle, \& Stephenson, 2001; Palmgreen \& Donohew, 2006; Wakefield, Loken, \& Hornik, 2010). Campaign awareness is a crucial contributor to the success of these campaigns. Media fragmentation and the everincreasing array of media outlets and platforms make it more difficult to get proper exposure therefore making the careful planning of content and distribution methods critical (Wakefield, Loken, \& Hornik, 2010). Formatting a campaign around a proven theory of persuasion such as the Elaboration Likelihood Model is an effective way to ensure that when a member of the target audience sees the PSA, the information is processed in a productive way (Palmgreen \& Donohew, 2006).

Through this study, we can learn which aspects of the campaign are effective and therefore where efforts can be focused or improved. This study can also be used as a 
template for the analysis of campaigns in the future. Additionally, it will give us an idea of which campaign is more effective for reaching college-aged young adults. Conducting research of the campaigns from an outside perspective will pose challenges to learning about the intentions of the campaign. All efforts will be made to learn as much about the techniques and marketing strategies employed by these two organizations prior to the research. 


\section{CHAPTER 2}

\section{REVIEW OF LITERATURE}

Mass media and television PSAs and health behavior change campaigns are effective at altering the behaviors of specific target audiences. The effectiveness of these campaigns hinges upon both 1) the ability to raise awareness of the campaign and 2) the content that piques interest while also activating emotional and cognitive processes that lead to internalization of the message (Palmgreen \& Donohew, 2006). Exposure depends on medium and frequency of message transmission and media channel usage varies by demographic. In other words, a campaign will be more likely to reach its intended audience if it is broadcast through the appropriate channel and during a time period when the audience is likely to be engaging with that medium. Messages targeting teens and young adults tend to be most effective when a campaign is coordinated across multiple digital platforms in tandem with other outreach methods such as "screening services, community programs, and policy support” (Robinson, Tansil, Elder, Soler, Labre, Mercer, \& Sokler, 2014).

In this study we assess the awareness of each of the two campaigns ('Real Cost' and 'The Truth') and examine which channels and messages are most effective. It compares factors such as awareness level and message content to determine what are the most important in predicting a positive attitude toward the health messages and an overall effective behavior change campaign. While awareness level and message content do 
work in tandem to create behavior change, both will be measured independently to determine how much they each affect the overall effectiveness of the campaign.

\section{Campaign Awareness}

The first measure to be assessed is the awareness of the campaign within the target audience. The concept that was used to assess this is market penetration. This was used in order to give us the level of awareness that the target audience had of each campaign (millennials and Gen Z). Market penetration is a key concept when measuring the effectiveness of a campaign. It is defined as the level of exposure that the target audience has to the campaign. This can be achieved through the "use of paid television, radio, and newspaper advertising combined with effective media relations" (Wootan, Reger-Nash, Booth-Butterfield, \& Cooper, 2005). Ad awareness is positively correlated to an increase in positive perceptions of the anti-smoking attitudes presented in the ad. In addition, the frequency of exposure to the advertisement is a strong indicator of attitude change (Hair, et. al., 2018). Conversely, additional research indicates that "lower exposure campaigns have less impact" (Wootan, et. al., 2005).

Binet and Field (2009) analyzed 880 IPA (Institute of Practitioners in Advertising) Effectiveness Awards cases and found that emphasizing and prioritizing market penetration, especially over brand loyalty, was a key factor in the success of campaigns and "advertising effectiveness in terms of sales and profit performance" (Binet \& Field, 2009). The importance of market penetration and campaign awareness in behavior change campaigns is well established in the literature (Binet \& Field, 2009; Dobbinson, et al., 2008; Jayaram, Manrai, A. K., \& Manrai, L. A., 2015; Peetz-Schou, 1997; Singh, et al., 2016; Wootan, et. al., 2005). With this in mind, it is important to look at the methods 
that each campaign is using to increase their market penetration. According to the FDA's "Real Cost" campaign, they use a variety of methods, including "Television ads, Online video ads, “The Real Cost” campaign's youth-targeted website, Social media, High schools nationwide (e.g., posters for school bathrooms)" in order to increase awareness of the campaign (Center for Tobacco Products, 2019). Their 2015 campaign budget states that, of their $\$ 85$ million, 68 percent was allocated to Video (TV, cinema, and online), 19 percent Online (banner ads, social media, search), 4 percent Out-of-home (e.g., bus shelters, malls, skate park murals), 2 percent radio (terrestrial), 1 percent print (magazines) and 4 percent opportunistic (which are "held in reserve to take advantage of media events or unexpected opportunities as the media year unfolds") (Santiago, Mahoney, Murray, \& Benoza, 2019). The Truth Initiative was contacted in an attempt to learn more about their budget breakdown by media outlet and other marketing practices, but they did not take the opportunity to respond.

Between the years of 2014 and 2016, middle and high school exposure to electronic cigarette advertising increased from 68 percent to over 78 percent. Participants in a study conducted by the National Institute of Health were asked how often they see advertisements for e-cigarettes from four sources. The sources were as follows: The Internet, newspapers/magazines, retail stores, and on television/at the movies. The survey found that in 2016 the most prevalent sources of exposure were retail stores, followed by the Internet and television (Marynak, Gentzke, Wang, Neff, \& King, 2018). This appears to differ from where the Real Cost attempted to market its advertisements, focusing heavily on its online presence. This makes sense considering that the e-cigarette 
companies are attempting to sell a product, the FDA and the Truth Initiative are selling attitudes and behaviors and require more than a single flashy image.

While we recognize that there are other strategies including audience segmentation, environmental supplements and formative research (Anker, Feeley, McCracken, \& Lagoe, 2016; Palmgreen \& Donohew, 2006) that are used by these campaigns to increase market penetration and campaign awareness, we have made a conscious choice to focus on medium. We chose this particular strategy due to the fact that this data was most easily accessible upon reaching out to members of the campaign as well as through survey. Considering that the Truth Initiative was not willing to divulge any of their marketing plans or budgets, we could not make any judgements on how they researched or segmented their target audience. Another important note is that the FDA used "at-risk" behaviors to target individuals more likely to currently be vaping, or to be more likely to start vaping (Santiago, et. al., 2019). This led to the thought process that individuals who have actively looked into vaping, or search for products or videos related to vaping, should be more likely to see these targeted campaign messages.

The other important aspect of awareness that was measured in this survey is ad recall. According to a 2011 study that analyzed indicators of online advertising success, of the three predictors identified (attitude towards the ad, ad recall, and click-through rates), ad recall is the most important predictor of advertising success (Lim, Yap \& Lau, 2011). A 2008 study into the effect of anti-smoking ad campaign recall in British Columbia found that smokers who recalled anti-smoking advertisements "decreased their perception of smoking as a coping mechanism and devalued their attachment to smoking" (Gagne, 2008). 
By testing each campaign for audience awareness, where participants have seen messages from each campaign, and assessing the likelihood of participants to recall arguments made in advertisements, we can determine which campaign is more effective at reaching its audience and through which platforms. This can inform future campaign managers which delivery methods and/or content to focus their attention on with campaign rollout.

\section{Elaboration Likelihood Model and Message Content}

The second major concept that was utilized in this study is Petty and Cacioppo's Elaboration Likelihood Model (ELM). Elaboration Likelihood Model and campaign awareness work hand in hand to ensure effectiveness. As suggested in this paper, there are two key components of a behavior change campaign. The first is that the target audience must be aware of the campaign. If they are not aware of the campaign and have not been exposed to it, they cannot process the messages. Conversely, just having your campaign seen by the audience is not enough to create any change in behavior or attitude toward the content. The content must be displayed in a way that encourages processing of the information presented. This study attempts to determine which campaign has a more effective strategy in regard to ensuring awareness, primarily through which channels are being used, and through the message content, which will be assessed in terms of what cues are being used in higher degree, peripheral or central.

This concept is used as a theoretical frame to make predictions about the content of ads and the likelihood of persuasion. Elaboration Likelihood Model states that people use mental processes to either accept or reject persuasive messages. Those messages can be processed through one of two routes; central or peripheral. Centrally routed messages 
attempt to use logic to persuade people while peripherally routed messages tend to rely on emotions. Central cues are effective when motivation, or elaboration likelihood, is high. Central cues are characterized by heavy use of evidence to back up the message. Peripherally routed messages can be effective when there is little motivation, or low elaboration likelihood, from the target audience to process the message. Elaboration Likelihood Model posits that the use of central cues has a stronger link to long term behavior change but require more motivation whereas peripheral cues do not lead to long term behavior change but have a strong short-term effect and can coax out an impulsive reaction (Petty \& Cacioppo, 1986; Rice \& Atkin, 2012).

Elaboration Likelihood Model accounts for the ways in which individuals process messages but it can be used as a framework for creating the messages as well. By using the main tenets of ELM, a marketing team can nudge an audience towards processing an argument through one route or another, or as Flynn and colleagues (Flynn, Worden, Bunn, Connolly \& Dorwaldt, 2011) suggest is most effective, through both in tandem. If a team is hoping to make an advertisement that is likely to lead to long term behavior change, they would prefer to use central cues and encourage their audience to process the messages centrally. Petty and Cacioppo (Petty \& Cacioppo, 1986) showed in their original research that those who process a message centrally are more likely to rationalize it and change their behavior.

There are limitations to this that have been addressed in the literature, however. The most relevant of those limitations is that one cannot accurately predict how an individual will process any given cue. Bitner and Obermiller point out that everyone comes into any given situation with specific and unique past experiences that may alter the way in which 
they process the information presented (Bitner \& Obermiller, 1985). This is why it is important to measure the motivation of individuals in addition to their cognitive processes and overall thoughts on the message. This study will ask students what their level of interest is regarding vaping; i.e., do they currently vape, have they looked into vaping, or do they have no interest. The thought is that those who vape or have shown interest in vaping will be more highly motivated to process the messages than those who do not vape. Studies into other activities have shown that motivation is a key factor into which route of processing an individual will take. Martín, Camarero, \& José also confirm that the central route is more important to individuals with higher involvement (Martín, Camarero, \& José, 2011). This indicates that the amount of interest shown in vaping should relate positively to effectiveness of videos that rank highly in central cues, as well providing evidence supporting the use of ELM in measuring the effectiveness of campaigns as long as motivation is taken into account.

Despite these limitations, Flynn and colleagues (Flynn, Worden, Bunn, Connolly \& Dorwaldt, 2011) have suggested that ELM is an invaluable method for determining the effectiveness of prevention messages. Upon evaluation, smoking prevention messages that were seen as being blended with use of central and peripheral cues were seen to be more effective and overall more appealing than the other messages. Message appeal is an overall assessment of how much a viewer enjoys the video (Flynn, et. al., 2011). It can be further defined as "an affective construct representing consumers' feelings of favorability/unfavourability toward the ad itself” (MacKenzie, Lutz, \& Belch, 1986). Additional prior research has suggested that attitude towards an advertisement, or 
message appeal, has been shown to be "an important mediator of message effectiveness" (Flynn, et. al., 2011) and is therefore worthwhile to consider in this research.

Flynn and colleagues used the student responses to break down each of the video advertisements that were shown into three categories: argument-rich, argument-lean, and blended. Argument-rich videos were considered videos with a heavy use of central cues. They relied heavily on the use of rational argumentation. In order for a video to score high on the argument-rich scale, it had to have high scores for the following categories: "has good facts" and "makes me think". If a video was scored as having good facts and making the viewer think, it was argument-rich and processed centrally. Argument-light videos relied on peripheral cues to make their point. These videos were said to have been processed peripherally and had high scores in the following categories: "looks cool" and "fun to watch". Videos that had high scores for both the argument-rich and the argumentlean prompts were considered to be blended.

Advertisements that were viewed as "argument-rich" were also seen to be more appealing overall than advertisements that were "argument-lean". The study also indicated that a major limitation of argument-rich advertisements is their inability to reach lower achieving students (Flynn, et. al., 2011). This means that while advertisements should be argument-rich, they should also be easily understood and easy to follow, hence the importance of blended messages. Several other studies have corroborated the validity of using Elaboration Likelihood Model as a measure for evaluating health campaigns. Palmgreen and Donohew suggested that many successful campaigns are based on theories including ELM (Palmgreen \& Donohew, 2006; Rice \& Atkin, 2012; Teng, Khong, \& Goh, 2014). 
This study is unique in that it uses previously established methods to analyze the effects of anti-vaping advertisements rather than anti-cigarette campaigns. Vaping is an interesting phenomenon because it does not have to follow the same restrictions as combustible cigarettes. For example, e-cigarettes can be advertised on "television, sports, music event sponsorships, in-store self-service displays, and advertisements placed outside of brick-and-mortar businesses at children's eye level" (Marynak, Gentzke, Wang, Neff, \& King, 2018). In addition, it is much easier to hide e-cigarettes due to their small size and the fact that the "smoke" disappears very quickly (Selekman, 2019). The prevalence of vaping ads is much higher than that of cigarettes, therefore it is especially important that we analyze these campaigns. The 'Real Cost' and Truth campaigns are the two most prevalent anti-vaping campaigns. They primarily use social media and the internet to convey their messages, which is imperative considering how common social media is with their target audience. In 2018, 85 percent of teens in the U.S. reported using YouTube, 72 percent reported using Instagram, 69 percent snapchat and 51 percent Facebook (Anderson \& Jiang, 2020).

\section{Statement of the Research Questions and Hypotheses}

This study focuses on analyzing the Federal Drug Administration's (FDA) 'Real Cost' Campaign and the Truth Initiative's “The Truth” campaign against Electronic Nicotine Delivery Systems (ENDS). Each campaign was assessed by two major axes, Awareness (Market Penetration) and Message Content in an attempt to answer whether or not young people are aware of the campaign and whether or not they believe the messages portrayed. In addition, it was a comparative analysis of the differential reach 
and believability of the two campaigns within the target audience. The study attempts to answer the following questions and address the following hypotheses:

RQ1: How aware are young people about the Real Cost and the Truth campaigns and what media are they being exposed to the messages through?

RQ2: How do members of the target audience perceive the argument richness of the arguments?

RQ3: Will higher frequency of ad exposure contribute to overall perception of message effectiveness?

H1: Argument-heavy and blended videos will score higher on overall message appeal than argument-lean videos.

$\mathrm{H} 2$ : People who have shown interest in vaping will be more likely to see and recall vaping ads than those who have shown no interest.

H3: The most impactful variables to determining effectiveness will be the central cues if motivation to process is high. 


\section{CHAPTER 3}

\section{METHODOLOGY}

\section{Design}

Since we attempted to look at two aspects of campaigns that contribute to their success, the study required two assessments. To assess message quality and route to persuasion, we performed a content analysis of campaign ads and a survey of young people in the target demographic for vaping ads.

\section{Content Analysis}

Since neither campaign provided insight into the reasoning behind each video, the content analysis was conducted in an effort to assess what was likely intended by the creators of the videos. The coders watched each video (see Appendix C) and used the 8factor scale (see Appendix A) to measure the rate at which each video used central and peripheral cues.

\section{Survey}

The content analysis was then followed by the survey which was used to determine how the target audience actually perceived each video as well as the awareness and perceived effectiveness of the campaign/video. The survey was conducted in two parts. Part one was administered prior to watching the video and the second part immediately following.

\section{Measurement}

The variables that were assessed in this study were persuasion strategy (central, peripheral, or blended), message perception, campaign awareness, motivation, and 
effectiveness. Both the content analysis and survey measured persuasion strategy, from two perspectives, and the survey measured the remaining.

\section{Content Analysis}

The first step was to conduct a content analysis of the previously selected videos from both campaigns. These videos were chosen in an effort to convey the diversity of ads run by both campaigns. The selected videos were independently coded by the investigator and two other trained coders with graduate level education in the Elaboration Likelihood Model. This content analysis was intended to inform us of what is in each video and how people should theoretically respond to and process the videos. The content analysis is based on prior research that has used ELM to determine which route of persuasion was used on the websites of ideological groups (Dunbar, Connelly, Jensen, Adame, Rozzell, Griffith, \& O’Hair, 2014).

In order to determine the extent to which each route to persuasion is used in the video, a set of questions based on scales used in prior research was utilized (Dunbar, et. al., 2014; Reynolds \& Burgoon, 1983). Each video was assessed on a 7-point Likert Scale using the same set of questions and was independently coded. There are 4 scaled questions pertaining to each route of persuasion. Each video was assessed on its use of central and peripheral cues and its scores from each question were averaged to give it both a central and peripheral score. Questions 1 through 4 address the central route to persuasion and questions 5 through 8 address the peripheral route (See Appendix A). Videos that score higher than a 3.5 for central cues but lower than a 3.5 for peripheral cues were categorized as "argument-heavy" videos. Videos that score lower than a 3.5 for central cues but higher than a 3.5 for peripheral cues were categorized as "argument- 
light" videos. Videos that score higher than a 3.5 for both categories were classified as "blended" videos.

The questions that hope to assess the central cues address credibility, critical thinking, argument quality and logic. These were chosen as they contribute to the central or logical route to persuasion. Credibility was defined for coders and participants using the following attributes: Appeals to authority [person or organization], the person or organization is seen as trustworthy or reliable, it is objective, it appeals to expertise/the information comes from an expert. The centrally targeted questions that followed this were: the video made a good argument, was rational and made me think. The peripheral questions visual representations, engagement, emotional appeals and entertainment. Visual engagement is defined for participants as the following: the look of it captures and holds my attention. Both the content analysis and the survey consisted of the same 8 questions, but the survey had an additional question regarding how much participants enjoyed the video.

\section{Survey}

The survey (attached as Appendix B) assessed the awareness that COM100 students have of both the FDA and Truth Initiative's campaigns, their motivation to process the advertisements, as well as their perceptions of the message content in selected campaign videos. First, the participants were asked how likely they are to vape in order to see if those who expressed more interest in vaping online are more likely to see the advertisements (H2). In an attempt to link expressing interest in vaping to increased antivaping message exposure, questions 1 and 2 ask about the consideration that each participant has put into vaping ranging from "currently vapes" to "no interest". 
Additionally, they were asked about online vaping related activity through use of search engines, i.e., searching or purchasing vaping related products online. Awareness of the campaign was measured through two questions: are you aware of the campaign? And have you seen a video from the campaign? Participants of the survey were also shown the logo for each of the campaigns (Appendix B) to help spark their memory, since each campaign uses their logo in all of their videos. Questions 6 through 15 assess the awareness and recall that the target audience had of each campaign (RQ1). After watching the video, participants were asked if they had seen that particular video. In addition, questions 8,13 and 18 ask for the source of awareness to determine which platforms are most effective (RQ1).

In addition to inquiring about awareness, the survey asks about the sources of said awareness in an attempt to answer the question of where, and through which channels, the students are being made aware of the campaign. In tandem, survey question 18 inquiries about the frequency of exposure to the video and campaign messages (RQ3). Frequency of ad exposure has previously been linked to increased positive perceptions of the presented attitudes (Hair, et al., 2018). Questions 9, 10, 14, 15 and 17 address the students' recall of material from the messages that they have seen, when applicable (RQ1). It asks the same questions about another anti-vaping campaign called "The Truth" which is funded by the Truth Initiative.

The next part of the survey was to determine whether or not students believe the messages portrayed in the campaign and assess the strength of the message. It also directly asks about the effectiveness of the video. The first question, question 16, was open-ended and attempts to assess what aspects of the video were the most engaging 
(H1). This allows students explain in their own words what they think were the most important parts of the video. If they found the argument to be the most important and engaging aspect, they will most likely have viewed the video centrally. On the other hand, if they find the animations, humor, emotions, etc. to be the most engaging part, then they will most likely have viewed the video peripherally.

The next set of questions relate back to awareness to measure the differences of awareness between each campaign within the context of specific videos. In addition, participants were also asked how often they have seen this commercial. The next set of questions in the survey utilize Petty and Cacioppo's Elaboration Likelihood Model to measure where each video scores in regard to participant perception of central and peripheral cues as well as overall message appeal (H1). These questions are the same as the ones used for the content analysis with questions 20 through 23 being central and questions 24 through 27 being peripheral, but an additional question was added, question 28, which was used to assess overall message appeal (Appendix B). Each video was scored individually, and then the four videos from each campaign were averaged together, giving us an average richness score for the campaign.

The final section of questions assesses the overall effectiveness of the campaign. In part 1 of the survey, prior to seeing the video, the participants were asked about their perceptions of vaping (questions 3 through 5). After watching the video, they were asked the same questions. Questions 3 through 5 and 29 through 31 were used to determine if the participants of the survey perceive the campaign as effective $(\mathrm{H} 3)$. If there is a significant change in the participants' perception of vaping, then the video and campaign can be seen as effective. The study attempts to determine whether or not there is a 
correlation between awareness and message content, and overall perceived effectiveness from the target population.

Once all of the data was collected from the 8 experimental sections, it was analyzed to determine which campaign has higher levels of awareness, where campaign exposure is occurring, and where campaign messages fall within ELM. Overall awareness of each campaign was assessed along with recall ability by averaging scores on the first part of the survey. Average scores were assessed for each campaign video that is shown, as well as an overall average for each individual campaign. If this study is consistent with prior findings, blended and argument-heavy videos should score significantly higher than argument-light videos (Flynn, et. al., 2011).

\section{Subjects}

The 138 participants were students the ages of 18 and 27 and enrolled in an entry level communication course at a midsized northeastern public university. They are the target audience of the anti-vaping campaigns in question and have been over the past few years. Specific demographic information about each participant was not collected to reassure participants about non-identifiability. The survey was administered online using SurveyMonkey and extra credit was offered as compensation to all students that participated.

\section{Procedures}

\section{Content Analysis}

The content analysis was conducted individually by three coders. The three coders consisted of the researcher, and two graduate students in the Communications Studies Master's program at the University of Rhode Island. Each coder had a Master's level 
understanding of the Elaboration Likelihood Model. Their assessments of the persuasion strategy were averaged and that composite score was used as the expert's assessment and considered as what was intended by the creators of the video.

\section{Survey}

The survey was distributed online through SurveyMonkey. In order to prevent fatigue, the survey was broken down into ten subject pools. The subject pools consisted of eight separate COM100 sections and two sections of an advanced Communications course. Eight of the ten groups were experimental. They were given both part one and part two of the survey (Appendix B) and were asked to watch a video. Each section watched a different video, and no video was watched by more than one experimental group. The video was watched in between parts one and two of the survey and participants were not able to move on to part two until after they had watched the video. Additionally, participants were informed that they would not able to move backwards in the survey. Once they moved on from part one of the survey, they would not be able to go back. They were instructed to approach part two as a blank slate. The last two of the ten sections were the control groups. They were not given part one of the survey. Each control group watched one video, previously selected at random from each campaign. One group watched a randomly selected video from the "Real Cost" campaign and the other group watched one randomly selected video from "The Truth" campaign. They then took part two of the survey. Data from the control group was used to ensure that part one of the survey did not bias the results found in part two. 


\section{CHAPTER 4}

\section{FINDINGS}

\section{Content Analysis Results}

Coder scores as well as those of the researcher were averaged to give an overall "expert" perspective. It is assumed that these scores are similar to the intended values of the video creators. The scores of both the coders and the participants can be seen in Table 1.

TABLE 1.

\begin{tabular}{|c|c|c|}
\hline Video & Participant ratings & Coder ratings - Avg. \\
\hline \multirow[t]{2}{*}{ RC Video 1} & Central $=5.67$ & Central $=4.92$ \\
\hline & Peripheral $=5.4$ & Peripheral = 5.17 \\
\hline \multirow[t]{2}{*}{ RC Video 2} & Central $=5.7$ & Central $=3.92$ \\
\hline & Peripheral $=5.3$ & Peripheral $=4.75$ \\
\hline \multirow[t]{2}{*}{ RC Video 3} & Central $=5.4$ & Central $=5.17$ \\
\hline & Peripheral $=5.55$ & Peripheral $=3.33$ \\
\hline \multirow[t]{2}{*}{ RC Video 4} & Central $=5.75$ & Central $=5.42$ \\
\hline & Peripheral $=5.38$ & Peripheral $=5.08$ \\
\hline \multirow[t]{2}{*}{ Truth Video 1} & Central $=4.9$ & Central $=5.33$ \\
\hline & Peripheral $=4.58$ & Peripheral $=4.67$ \\
\hline \multirow[t]{2}{*}{ Truth Video 2} & Central $=5.29$ & Central $=4$ \\
\hline & Peripheral $=4.93$ & Peripheral $=4.58$ \\
\hline
\end{tabular}




\begin{tabular}{|l|c|c|}
\hline Truth Video 3 & Central $=5.76$ & Central $=5.25$ \\
\cline { 2 - 3 } & Peripheral $=5.70$ & Peripheral $=2.58$ \\
\hline Truth Video 4 & Central $=4.63$ & Central $=1.75$ \\
\cline { 2 - 3 } & Peripheral $=5.43$ & Peripheral $=3.58$ \\
\hline
\end{tabular}

This data shows us that participants were more likely to identify and process the central cues of the video than the peripheral ones. The deviation was calculated by subtracting the peripheral score from the central score for each video. A positive score indicates a higher central score and a negative score indicates a higher peripheral one. In only one video did participants definitively mark a video as peripheral over central. The coders on the other hand were more likely to identify those videos that relied heavily on peripheral cues. An intraclass correlation coefficient test was run to determine the reliability of the coding. The coding was found to be reliable. The results were the following:

Coding peripheral cues Cronbach's alpha $=.814$

Coding central cues Cronbach's alpha $=.859$

Coding deviation scores Cronbach's alpha $=.844$

TABLE 2.

\begin{tabular}{|c|r|r|r|}
\hline video & $\begin{array}{c}\text { Part } \\
\text { deviation }\end{array}$ & $\begin{array}{c}\text { coder } \\
\text { deviation }\end{array}$ & How do the participants differ? \\
\hline rc1 & 0.27 & -0.25 & Participants see it more central \\
\hline rc2 & 0.4 & -0.83 & Participants see it more central \\
\hline rc3 & -0.15 & 1.92 & Participants see it more peripheral \\
\hline rc4 & 0.37 & 0.33 & Both see it more central \\
\hline $\mathrm{t} 1$ & 0.32 & 0.67 & Both see it more central \\
\hline $\mathrm{t} 2$ & 0.36 & -0.58 & Participants see it more central \\
\hline
\end{tabular}




\begin{tabular}{|r|r|r|r|}
\hline t3 & 0.06 & 2.67 & $\begin{array}{r}\text { Participants see it more evenly blended } \\
\text { while coders see it as central }\end{array}$ \\
\hline t4 & -0.8 & -1.83 & $\begin{array}{r}\text { Participants see it as more evenly blended } \\
\text { while coders see it as peripheral }\end{array}$ \\
\hline
\end{tabular}

\section{Survey Results}

Participation amongst the convenience sample of COM100 students was fairly low. Of a potential 250 participants, only $55 \%$, or 138 students, completed the survey. Of the 138 participants only 14 reported that they "currently vape". Additionally, 7 reported that they "have looked into vaping" and 8 reported having "thought about vaping". This left 68 participants to fall into the "no interest in vaping" category while 41 participants did not answer the question. As a result of the low number of participants that currently vape, one of the measures of perceived effectiveness, 'considering quitting vaping', had to be omitted in consideration of the video and campaign's effectiveness.

\section{Awareness}

It was found that $76 \%$ of the participants were aware of the FDA's Real Cost campaign and only $45 \%$ were aware of the Truth Initiative. Furthermore, $70 \%$ reported having seen a video from the Real Cost and only $37 \%$ had seen one from the Truth Initiative. The most common place that participants had been exposed to both campaigns was on TV, where 31 people reported having seen Real Cost (RC) commercials and 20 had seen Truth videos. The next most common platform was Youtube which accounted for 16 participants who said they had seen videos from the RC campaign and 17 who had seen Truth videos. Other places that participants recalled seeing both videos/advertisements were Facebook, Spotify, TikTok, Snapchat, Instagram, Hulu, school and Twitter. 


\section{Argument Richness}

The participants Argument Richness, also mentioned as persuasion strategy, scores can be seen in Figure 1 below.

TABLE 3.

\begin{tabular}{|c|c|}
\hline \multirow[t]{2}{*}{ RC Video 1} & Central $=5.67$ \\
\hline & Peripheral $=5.4$ \\
\hline \multirow[t]{2}{*}{ RC Video 2} & Central $=5.7$ \\
\hline & Peripheral $=5.3$ \\
\hline \multirow[t]{2}{*}{ RC Video 3} & Central $=5.4$ \\
\hline & Peripheral $=5.55$ \\
\hline \multirow[t]{2}{*}{ RC Video 4} & Central $=5.75$ \\
\hline & Peripheral $=5.38$ \\
\hline \multirow[t]{2}{*}{ Truth Video 1} & Central $=4.9$ \\
\hline & Peripheral $=4.58$ \\
\hline \multirow[t]{2}{*}{ Truth Video 2} & Central $=5.29$ \\
\hline & Peripheral $=4.93$ \\
\hline \multirow[t]{2}{*}{ Truth Video 3} & Central $=5.76$ \\
\hline & Peripheral $=5.70$ \\
\hline \multirow[t]{2}{*}{ Truth Video 4} & Central $=4.63$ \\
\hline & Peripheral $=5.43$ \\
\hline
\end{tabular}


The average score for the Real Cost Campaign was Central $=5.63$ and Peripheral $=5.41$

and the average score for the Truth campaign was Central $=5.14$ and Peripheral $=5.16$. This means that although the Real Cost campaign scored higher on average, both campaigns were viewed to use a blended message style of both central and peripheral cues.

\section{Ad Exposure and Effectiveness}

In order to determine whether exposure to anti-vaping advertisements prior to this experiment had an effect on the perceived effectiveness of the ad shown, pre-test exposure questions were compared to effectiveness. The pre-test exposure question that was used as whether or not the participant had seen a video from either of the campaigns, prior to showing them the selected ad. Effectiveness was measured by averaging the score of two out of the final three questions. The effectiveness questions originally consisted of whether the participant was "concerned about the safety of vaping", "considering quitting", and would try to "convince a friend that was interested in vaping not to". The "considering quitting" question was removed from the composite effectiveness score because there was such a low percentage of participants who reported that they currently vape. Therefore, most participants could not be convinced to quit.

A linear regression test was run between the independent variable of exposure and the dependent variable of perceived effectiveness and the results suggested a positive relationship. Those participants who had prior exposure to the campaign were more likely to respond positively to the shown video than those who were seeing it for the first time. The result was statistically significant $(\beta=0.246, p=0.02, \mathrm{~F}[1,87]=5.62)$. 
This finding is in line with ELM. The model states that behavior change does not occur in the short term. Health campaigns require long term repeated exposure to be truly effective in creating an actual change in behavior, but this study was able to show that, even on first viewing. Although we did not test for long term effects, we did see that those who reported being previously exposed to the PSAs showed more positive reactions upon repeat viewing than those seeing it for the first time.

\section{Argument Richness and Message Appeal}

Previous research has suggested that videos that are perceived to have blended or argument-heavy messages also have higher overall message appeal. In an attempt to replicate this result, participants were asked to rate the video in terms of how much they enjoyed watching it. This was the value used to determine overall message appeal. After running linear regression analysis, it was determined that this was not the case. Videos with high central scores had no significant effect on the overall message appeal $(ß=$ $0.056, p=0.538, \mathrm{~F}[2,110])$, therefore rejecting $\mathrm{H} 1$. When the same analysis was run for the peripheral scores, the results were found to be significant $(\beta=0.6, p=0.000$, $\mathrm{F}[2,110]$. It is likely that this is due to there being such little variation between the videos. Although the videos were chosen to be as representative of the campaigns as possible while displaying some variety in persuasive techniques, they are all high-quality videos from wealthy campaigns. These videos were specifically chosen and aired because they are good videos. In general, the videos from each campaign tend to take a blended approach as this has been shown to be effective in the past. Additionally, it is likely that the average viewer is not as capable or as motivated to pick out the difference in persuasive strategy used, even when directly asked about various factors. 
Further analysis was done to determine if any individual characteristics had more of an impact than the others. Three of the factors were found to have a significant effect on enjoyment. The peripheral cues "entertaining" and "emotional appeal" as well as the central cue "made me think" were seen to have a significant positive correlation to the overall message appeal, or enjoyment of the video.

\section{TABLE 4.}

\begin{tabular}{|c|c|}
\hline \multirow[t]{3}{*}{ RC Video 1 - blended } & Central $=5.67$ \\
\hline & Peripheral $=5.4$ \\
\hline & Message appeal $=5.17$ \\
\hline \multirow[t]{3}{*}{ RC Video 2 - blended } & Central $=5.7$ \\
\hline & Peripheral $=5.3$ \\
\hline & Message appeal $=5$ \\
\hline \multirow[t]{3}{*}{ RC Video 3 - blended } & Central $=5.4$ \\
\hline & Peripheral $=5.55$ \\
\hline & Message appeal $=5.4$ \\
\hline \multirow[t]{3}{*}{ RC Video 4 - blended } & Central $=5.75$ \\
\hline & Peripheral $=5.38$ \\
\hline & Message appeal $=4.75$ \\
\hline \multirow[t]{3}{*}{ Truth Video 1 - blended } & Central $=4.9$ \\
\hline & Peripheral $=4.58$ \\
\hline & Message appeal $=4.67$ \\
\hline Truth Video 2 - blended & Central $=5.29$ \\
\hline
\end{tabular}




\begin{tabular}{|l|c|}
\hline \multirow{4}{*}{ Truth Video 3 - blended } & Peripheral $=4.93$ \\
\cline { 2 - 2 } & Message appeal $=4.14$ \\
\cline { 2 - 2 } & Central $=5.76$ \\
\cline { 2 - 2 } & Peripheral $=5.70$ \\
\hline Truth Video 4 - blended & Message appeal 4.47 \\
\cline { 2 - 2 } & Central $=4.63$ \\
\cline { 2 - 2 } & Peripheral $=5.43$ \\
\cline { 2 - 2 } & Message appeal $=4.81$ \\
\hline
\end{tabular}

\section{Interest in Vaping and Exposure}

The FDA reported that they used targeted marketing to choose who would be more likely to see their ads. Interest in vaping was determined by a composite of online activities related to interest. An individual's interest consisted of an average score of the four interest questions regarding purchasing vaping products, searching for vaping products, watching vaping videos, and searching for vaping videos. An ANOVA test was run between that level of interest and exposure to that campaign (exposure being the same value as previously defined). There was no significance found in the differences between individual scores $(\mathrm{F}[1,95]=1.310, p=0.255)$ and $\mathrm{H} 2$ was rejected. This lack of significance is likely due to the fact there were so few people who reported showing any interest in vaping at all. This study directly followed numerous reports of a deadly disease/condition associated with vaping that likely drove many people to quit vaping.

\section{Motivation, Argument Richness and Effectiveness}

Stepwise regression was run with the eight argument richness variables (credible, good argument, rational, made me think, emotional appeal, entertaining, engaging, visual 
representations) as predictors of effectiveness. The first variable entered into the model was emotional appeal which was a statistically significant indicator of effectiveness that accounts for $5 \%$ of the variation $(B=0.246, p=0.0090, F[1,111]=7.15)$. Therefore, $H 3$ was rejected. Of the other 7 variables, none contributed statistically significant improvements to the model. Regression analysis was then run to determine the effect of motivation on the effectiveness of the PSAs. It was found that motivation rate was a significant predictor and was strongly associated with effectiveness $(\mathrm{F}[1,111]=123.41$; $\left.p=0.000 ; \mathrm{r}^{2}=0.524\right)$. Following that test, the sample was split at the mean motivation level and stepwise regression analysis was run between motivation, the eight richness variables and effectiveness. The group that was high in motivation found the messages effective and those with low motivation did not. There were no significant variables in the low motivation group, but emotional appeal was forced in an attempt to compare it with the high motivation group $\left(\mathrm{F}_{1,48}=0.399 ; \mathrm{p}=0.531 ; \mathrm{r}^{2}=-0.012\right)$. In the high motivation group, Emotional appeal had a significant impact on effectiveness $\left(\mathrm{F}_{1,65}=\right.$ $\left.5.427 ; \mathrm{p}=0.023 ; \mathrm{r}^{2}=0.063\right)$ that was not seen in the low motivation group.

\section{Comparative Analysis}

It was found that participants of the study were more aware of the Real Cost campaign than the Truth campaign and reported seeing it at a much higher rate. Roughly three quarters (76\%) of the participants were aware of the Real Cost campaign and 70 percent had seen a video, while less than half (45\%) reported being aware of the Truth Campaign and only 37 percent had seen a video from the campaign. Although the average score for overall effectiveness of the videos leaned in favor of the Real Cost campaign, this was found to be not significant. An independent t-test was run on the 
differences in overall effectiveness and there was no significant difference in the effectiveness of the videos for each campaign, $\mathrm{t}(81)=0.715, p=0.476$.

\section{Correlation Analysis}

Since the individual factors used to assess the persuasion strategy implemented in the video were supposed to represent either a central or a peripheral cue, there was concern that perhaps the individual factors would be too similar to account for any variation. In order to ascertain whether or not this was the case, a correlation matrix was run between all of the factors measured. After running the matrix, no multi-collinearity was discovered, indicating enough of a difference between each of the 8 factors to confidently utilize the data collected from our individual factor assessments. Below are the results of that correlation matrix.

\section{Table 5.}

\section{Correlations}

\begin{tabular}{|c|c|c|c|c|c|c|c|c|c|}
\hline & & $\begin{array}{l}\text { Credib } \\
\text { le }\end{array}$ & $\begin{array}{l}\text { Good } \\
\text { Argume } \\
\text { nt }\end{array}$ & $\begin{array}{l}\text { Ration } \\
\text { al }\end{array}$ & $\begin{array}{l}\text { Mad } \\
\text { e Me } \\
\text { Thin } \\
\mathrm{k} \\
\end{array}$ & $\begin{array}{l}\text { Entertaini } \\
\text { ng }\end{array}$ & $\begin{array}{l}\text { Engagi } \\
\text { ng }\end{array}$ & $\begin{array}{l}\text { Visual } \\
\text { representatio } \\
\text { ns }\end{array}$ & $\begin{array}{l}\text { Emotion } \\
\text { al appeal }\end{array}$ \\
\hline \multirow[t]{3}{*}{ Credible } & $\begin{array}{l}\text { Pearson } \\
\text { Correlati } \\
\text { on } \\
\end{array}$ & 1 & $.588 * *$ & $.613 * *$ & $\begin{array}{l}.389 * \\
*\end{array}$ & $.294 * *$ & $.375^{* *}$ & $.417 * *$ & $.392 * *$ \\
\hline & $\begin{array}{l}\text { Sig. (2- } \\
\text { tailed) }\end{array}$ & & .000 & .000 & .000 & .001 & .000 & .000 & .000 \\
\hline & $\mathrm{N}$ & 120 & 120 & 119 & 119 & 116 & 120 & 119 & 120 \\
\hline \multirow[t]{3}{*}{$\begin{array}{l}\text { Good } \\
\text { Argument }\end{array}$} & $\begin{array}{l}\text { Pearson } \\
\text { Correlati } \\
\text { on }\end{array}$ & $.588 * *$ & 1 & $.695^{* *}$ & $\begin{array}{l}.615^{*} \\
*\end{array}$ & $.247 * *$ & $.365^{* *}$ & $.340 * *$ & $.466^{* *}$ \\
\hline & $\begin{array}{l}\text { Sig. (2- } \\
\text { tailed) }\end{array}$ & .000 & & .000 & .000 & .008 & .000 & .000 & .000 \\
\hline & $\mathrm{N}$ & 120 & 120 & 119 & 119 & 116 & 120 & 119 & 120 \\
\hline \multirow[t]{3}{*}{ Rational } & $\begin{array}{l}\text { Pearson } \\
\text { Correlati } \\
\text { on }\end{array}$ & $.613^{* *}$ & $.695^{* *}$ & 1 & $\begin{array}{l}.605^{*} \\
*\end{array}$ & $.266 * *$ & $.412^{* *}$ & $.422 * *$ & $.403 * *$ \\
\hline & $\begin{array}{l}\text { Sig. (2- } \\
\text { tailed) }\end{array}$ & .000 & .000 & & .000 & .004 & .000 & .000 & .000 \\
\hline & $\mathrm{N}$ & 119 & 119 & 119 & 118 & 115 & 119 & 118 & 119 \\
\hline \multirow[t]{2}{*}{$\begin{array}{l}\text { Made Me } \\
\text { Think }\end{array}$} & $\begin{array}{l}\text { Pearson } \\
\text { Correlati } \\
\text { on } \\
\end{array}$ & $.389 * *$ & $.615^{* *}$ & $.605 * *$ & 1 & $.248^{* *}$ & $.363^{* *}$ & $.336 * *$ & $.542 * *$ \\
\hline & $\begin{array}{l}\text { Sig. (2- } \\
\text { tailed) }\end{array}$ & .000 & .000 & .000 & & .008 & .000 & .000 & .000 \\
\hline
\end{tabular}




\begin{tabular}{|c|c|c|c|c|c|c|c|c|c|}
\hline & $\mathrm{N}$ & 119 & 119 & 118 & 119 & 115 & 119 & 118 & 119 \\
\hline \multirow[t]{3}{*}{ Entertaining } & $\begin{array}{l}\text { Pearson } \\
\text { Correlati } \\
\text { on } \\
\end{array}$ & $.294 * *$ & $.247 * *$ & $.266^{* *}$ & $\begin{array}{l}.248^{*} \\
*\end{array}$ & 1 & $.514^{* *}$ & $.424 * *$ & $.352^{* *}$ \\
\hline & $\begin{array}{l}\text { Sig. (2- } \\
\text { tailed) } \\
\end{array}$ & .001 & .008 & .004 & .008 & & .000 & .000 & .000 \\
\hline & $\mathrm{N}$ & 116 & 116 & 115 & 115 & 116 & 116 & 115 & 116 \\
\hline \multirow[t]{3}{*}{ Engaging } & $\begin{array}{l}\text { Pearson } \\
\text { Correlati } \\
\text { on }\end{array}$ & $.375^{* *}$ & $.365^{* *}$ & $.412^{* *}$ & $\begin{array}{l}.363^{*} \\
*\end{array}$ & $.514^{* *}$ & 1 & $.630^{* *}$ & $.502^{* *}$ \\
\hline & $\begin{array}{l}\text { Sig. (2- } \\
\text { tailed) }\end{array}$ & .000 & .000 & .000 & .000 & .000 & & .000 & .000 \\
\hline & $\mathrm{N}$ & 120 & 120 & 119 & 119 & 116 & 120 & 119 & 120 \\
\hline \multirow[t]{3}{*}{$\begin{array}{l}\text { Visual } \\
\text { representatio } \\
\text { ns }\end{array}$} & $\begin{array}{l}\text { Pearson } \\
\text { Correlati } \\
\text { on } \\
\end{array}$ & $.417 * *$ & $.340^{* *}$ & $.422 * *$ & $\begin{array}{l}.336^{*} \\
*\end{array}$ & $.424 * *$ & $.630^{* *}$ & 1 & $.512^{* *}$ \\
\hline & $\begin{array}{l}\text { Sig. (2- } \\
\text { tailed) }\end{array}$ & .000 & .000 & .000 & .000 & .000 & .000 & & .000 \\
\hline & $\mathrm{N}$ & 119 & 119 & 118 & 118 & 115 & 119 & 119 & 119 \\
\hline \multirow[t]{3}{*}{$\begin{array}{l}\text { Emotional } \\
\text { appeal }\end{array}$} & $\begin{array}{l}\text { Pearson } \\
\text { Correlati } \\
\text { on } \\
\end{array}$ & $.392^{* *}$ & $.466^{* *}$ & $.403 * *$ & $\begin{array}{l}.542^{*} \\
*\end{array}$ & $.352^{* *}$ & $.502^{* *}$ & $.512^{* *}$ & 1 \\
\hline & $\begin{array}{l}\text { Sig. (2- } \\
\text { tailed) }\end{array}$ & .000 & .000 & .000 & .000 & .000 & .000 & .000 & \\
\hline & $\mathrm{N}$ & 120 & 120 & 119 & 119 & 116 & 120 & 119 & 120 \\
\hline
\end{tabular}

** Correlation is significant at the 0.01 level (2-tailed)

A factor analysis yielded results that were consistent with the Elaboration

Likelihood Model. The component matrix identified two components. The first

component had all eight persuasive message features loading positively. This component seems to capture persuasion as all eight components have been identified as persuasive techniques. The second component split as predicted between the components that appeal to rational persuasion and components that appeal to emotional persuasion. The matrix is given in Table 6 .

\section{Table 6.}

\section{Component Matrix}

\begin{tabular}{ll|l} 
& \multicolumn{2}{c}{ Component } \\
& 1 & 2 \\
\hline Credible & .727 & -.223 \\
\hline Good Argument & .788 & -.392 \\
\hline Rational & .817 & -.308 \\
\hline
\end{tabular}




\begin{tabular}{l|r|r}
\hline Made Me Think & .742 & -.362 \\
\hline Entertaining & .569 & .589 \\
\hline Engaging & .727 & .472 \\
\hline $\begin{array}{l}\text { Visual } \\
\text { representations }\end{array}$ & .712 & .411 \\
\hline Emotional appeal & .739 & .028 \\
\hline
\end{tabular}

Extraction Method: Principal

Component Analysis.

\section{Control Test}

Analysis was run to determine whether or not part 1 of the survey that was distributed to the experimental groups had any sensitization effect on their effectiveness responses post seeing the video. The two control groups were shown one of two videos that were also shown to the experimental groups, one from each campaign. After running t-tests between the control group and corresponding experimental groups, no significant sensitization effect was found, meaning that Part 1 did not change the way that the experimental groups perceived the video's effectiveness. The first control group analysis resulted in a $\mathrm{t}(23)=0.140, p=0.688$. The second control group analysis yielded a similar result of $\mathrm{t}(35)=1.07, p=0.676$.

\section{Summary of Findings}

This study did yield some interesting findings. It was found that participants of the survey were more likely to rate the video as being high in central cues than the coders were, however both campaigns were primarily viewed as being blended in persuasion strategy. The videos were not perceived as intended by the "experts". Additionally, participants were much more aware of the Real Cost campaign than the Truth Initiative. With this in mind, awareness of and exposure to the campaign was found to be positively related to perceived effectiveness of the videos. Counter to our hypothesis, having a high 
central score had no significant effect on overall message appeal but the peripheral scores did. The two peripheral cues "entertaining" and "emotional appeal" were found to be particularly significant in addition to the central cue "made me think". Interest in vaping was not found to have a significant effect on the likelihood of being exposed to the campaign videos. In addition, the only factor that had a significant role in predicting the effectiveness of the video was the peripheral cue "emotional appeal'. 


\section{CHAPTER 5}

\section{CONCLUSION}

No true determination could be made between which of the two campaigns was more effective. Although the Real Cost campaign did have a higher rate of awareness than the Truth campaign, the slight differences in effectiveness that were noted were not significant. Without knowing how the Truth Initiative broke down its campaign, it is impossible to tell why the Real Cost had such an advantage in awareness. Additionally, this experiment was not able to replicate the results found in Flynn. There could be several possibilities for this. The sample size of this experiment was much smaller than that of the Flynn experiment. This could also potentially be a reason for the lack of variation in response. More responses would have allowed for more potential variation in the reported scores for interest levels as well as interpretations of the PSAs. Despite this, this study did unearth some worthwhile findings.

It was noted during the analysis of the collected data that, on average, the survey participants rated the videos as more central than the coders did. This is a phenomenon that has been documented in the past. In 1978, Ellen Langer conducted a study known colloquially as the copy machine study that demonstrated people's inability to distinguish between strongly and poorly supported arguments. Adults were observed to see whether or not they would let someone skip the line for the copier machine given three different reasons; one without any information, one with placebic or nonsensical information, and one with a sufficient and legitimate reason. Although participants were less likely to let 
people cut without providing a reason, they let them cut the line at roughly the same rate regardless of the reason (Langer, Blank, \& Chanowitz, 1978). This means that they did not bother processing the logic behind the reason given by the would-be line-skipper. The nonsensical and logical reasoning were both accepted over 90 percent of the time and participants could not, or did not, distinguish the strength of the argument. It is therefore not a stretch to assume that participants in this study were also not properly distinguishing the difference between the strong and weakly supported arguments. It is also possibly that the participants of the study are not actively viewing the video, but rather viewing it passively.

One discovery that we did make was that emotional appeal, in a one-time video showing, does have a significant positive impact on the perception of effectiveness. This is consistent with Elaboration Likelihood Model. In short term exposure, peripheral cues have stronger effects. Central or cognitive cues, while being more effective methods for behavior change, require repeated exposure in order to be effective. We also saw that prior exposure was a contributor to the participants having a more positive response to the video in a single showing, further confirming ELM's assertion that frequency of exposure can lead to a participant being more receptive to the message.

This leads us to the most interesting finding of the study. While the participants did recognize the cognitive central arguments and were able to note that they were present in many of the videos, they did not have any significant effect, even in those who had previously seen the videos. The peripheral cues, and specifically the Emotional Appeal of the videos were the most, and only, significant predictor of video effectiveness. Therefore, it is the recommendation of this study for these campaigns to focus heavily on 
emotional appeal in all of their videos. Even when the students recognized the rational arguments, they did not process them. It was the emotional aspects of the video that allowed the students to take in the message. These PSAs should have heavy focus on the emotional component with a simple message and the videos should be played frequently.

The next closest factor contributing to perceptions of effectiveness was the peripheral cue, visual representations. Visual representation was not a statistically significant contributing factor, but considering that it was the next closest factor, it may be interesting to consider. Unlike Emotional Appeal, visual representations actually had a negative correlation with effectiveness. The often-disturbing images did not seem to have the intended effect. Perhaps this is because, unlike with cigarette smoking, the actual effects of vaping are not as visual. There is still much confusion around the effects and therefore it might be difficult to visualize it. This could be an interesting aspect of the research to look into further.

Enjoyment and overall message appeal were mainly affected by three factors; Entertaining, Emotional Appeal, and Made me Think. The peripheral cues Entertaining and Emotional Appeal were positively related to enjoyment and accounted for $43 \%$ of the variance. Although the overall central scores were not statistically significant, the central factor Made me Think was positively correlated with enjoyment and accounted for $15 \%$ of the variance. This also lent itself towards ELM. It would be worth studying students over a longer period of time to see if that factor Made me Think had a stronger effect upon repeated viewing. With this in mind, it would be beneficial for campaigns to target their videos on these factors. The videos should be entertaining, have high levels of emotional appeal and they should make the viewer think. It is important to keep in mind 
that these results analyze short term effects of these videos and we also did not control for repeated viewing. Upon repeated viewing, the most influential factors may change, but these are the most important factors to make a difference with single viewing.

Although participants did report higher frequencies of viewing the RC campaign, there is little evidence to suggest why this was the case. Many participants also reported seeing videos from the Truth campaign but not at the same frequency. Since the Truth initiative did not disclose its marketing budget, there is no way to tell if this is due to a lack of funding on their part or if the RC campaign was simply better at targeting its audience. This result was contradictory to what had been expected going into the study. From personal experience, I have seen many more Truth Initiative videos as advertisements on social media sites, YouTube and through streaming services. I had only experienced viewing the $\mathrm{RC}$ videos on cable television and occasionally as YouTube ads. One possible explanation for this is that the $\mathrm{RC}$ videos have more staying power. Since the "Real Cost" is distributed and backed by the FDA, it has more authoritative power than the Truth campaign which is operated by an independent nonprofit. It was also noted that the $\mathrm{RC}$ campaign had a higher average score on message appeal than the Truth campaign did.

It seems from this study that these PSAs are most effective and impactful with teens who showed interest in vaping or had recently started vaping. Their elaboration likelihood is higher because they are more motivated to process the messages. Individuals who have no interest in vaping will not be affected the messages and will therefore disregard them. Similarly, individuals who have been vaping for a long time are likely to follow in the footsteps of long-time smokers. They will disregard the messages because 
they are either too ingrained in their habit, are addicted, or already know that it is bad for them but will not change. This study has also shown that even if an individual's personal perception of vaping or vaping behavior does not change, these PSAs are likely to cause teens and young adults to convince their friends to not try vaping if they say that they are considering it.

One major recommendation that can be made to future campaigns would be in regard to which media outlets to target. From the research it was clear that television, streaming services, YouTube and social media outlets were the most common places that students were seeing and recalling these PSAs. Although the Truth Initiative did not divulge their marketing spending breakdown, this did seem to line up with the Real Cost's spending. Even with only 19 percent of their budget being allocated to "online ads", it was a strong contributor to their market penetration. It may be worth investing slightly more of the budget on this medium, especially considering the increase in smartphone prevalence and usage amongst their target audience.

\section{Limitations}

There were several limitations for this study. The first being that after the study was proposed and approved, the apparent risks of vaping grew exponentially. There were numerous reports of young people being hospitalized and even dying with a mystery lung illness that was related to vaping. This seemed to drastically reduce the number of teens and young adults that vaped. I believe that this is at least partially responsible for the low participation rate from people who vape. The presence of COVID-19 also posed problems of its own. Additionally, there could be other factors contributing to the low levels of self-reported vaping. Despite the promise of anonymity, it is possible that 
students did not want to admit the fact that they vape to an authority figure. Considering that vaping is often looked negatively upon by older generations and by health professionals, social desirability bias may have been preventing them from answering that question honestly.

Although research confirming this was not available until recently, it was well known that COVID-19 was a disease that affected the respiratory system. Knowing that vaping and smoking of any kind is detrimental to the lungs, it is possible that fringe or new users of electronic cigarettes, may have altered the health behaviors in an attempt to protect themselves from this novel and deadly virus. Additionally, this survey was initially meant to be delivered in person. Delivering this survey in person would have most likely increased both the participation rate, as well as the amount of time that each participant spent on the survey. I believe that having the presence of a researcher as well as structured time would increase the quality of participant responses. Unfortunately, at the same time that the survey was ready to be distributed, the novel coronavirus, COVID19 hit pandemic levels. Classes at the University of Rhode Island transitioned online. As a result, the survey had to be distributed this way as well. The transition to online class was a difficult one for students and this could certainly be a contributing factor to lower participation rates and lower quality responses. Without the presence of a researcher or an authority presence, participants may have felt less of an obligation to take their time and formulate higher quality responses. Students felt that it was much more difficult to focus given the pandemic status of COVID-19 and the online format of classes.

An additional factor that may have led to the low variation in effectiveness scores was the scaling. In order to not overwhelm the participants, a standard 7-point Likert 
scale was used instead of the 100-point scale that Flynn et. al used in their experiment. Therefore, there is less variation in the answers as they all clustered around the middle. It is possible that with a larger scale, answers would have been more spread out and more minute differences could be made out.

It is also important to note that the content of the videos did not vary that much. There were no truly bad videos in the sample and for the most part most of the videos were identified by coders as being blended in terms of their cues. Including videos that were purely rational or raw emotional appeals might have been more likely to illustrate the difference between blended videos like those in the sample. Presenting videos like this would create a problem with external validity because they are not an accurate representation of a video that is a part of either campaign. No successful campaign would

put money behind releasing a video that is intentionally less effective. Therefore, it would only be worthwhile to include such videos if an actual legitimate anti-vaping campaign were to release them.

\section{Future research}

Future research should be conducted into the effect of the campaign's marketing budget. It would be very interesting to see where the campaigns are spending their resources and what platforms lead to the highest level of awareness. It would also be worthwhile to look further into why such a larger percentage of teens reported seeing the Real Cost and not Truth considering that in all of the research I have done, it seemed that Truth Campaign came up more frequently on more social media applications than the Real Cost. In fact, I do not think that I organically saw any Real Cost videos, but several Truth videos would come up as advertisements during my research, yet participants 
reported seeing Real Cost videos at a much higher rate. Does this have to do with the marketing strategy? With branding? Does the fact that the Real Cost comes from the FDA have anything to do with it? Are Truth videos simply more forgettable than Real Cost videos? Does the Real Cost just have a higher budget? It would be very interesting to look into the underlying reasons for these discrepancies.

It would also be worthwhile to try this experiment again, under better circumstances. The limitations that this experiment was conducted under due to the novel coronavirus may have seriously impacted the results of the study. Therefore, this experiment could be run again to determine whether or not these results are skewed given the circumstances. In addition, it is possible that the presence of a new respiratory illness may have changed participant's perceptions of vaping more than the campaigns themselves. Questions could be asked whether the unknown respiratory illness related to vaping had an impact on their decisions, as well as questions specifically regarding coronavirus. 


\section{APPENDICES}

\section{Appendix A}

1. The video had strong, believable information and is credible (credibility refers to the amount of these appeals used: Appeals to authority [person or organization], the person or organization is seen as trustworthy or reliable, it is objective, it appeals to expertise/the information comes from an expert).
Strongly Disagree
(1)
(2)
(3)
(4)
(5)
(6)
(7) Strongly Agree

2. The video made a good argument.
Strongly Disagree
(1)
(2)
(3)
(4)
(5)
(6)
(7) Strongly Agree

3. The video was rational.
Strongly Disagree
(1)
(2)
(3)
(4)
(5)
(6)
(7) Strongly Agree

4. The video made me think.
Strongly Disagree
(1) (2)
(3)
(4)
(5)
(6)
(7) Strongly Agree

5. The video was entertaining.
Strongly Disagree
(1)
(2)
(3)
(4)
(5)
(6)
(7) Strongly Agree

6. The video was visually engaging (the look of it captures and holds my attention).
Strongly Disagree
(1)
(2)
(3)
(4)
(5)
(6)
(7) Strongly Agree

7. The video primarily uses visual representations to convey its message.
Strongly Disagree
(1)
(2)
(3)
(4)
(5)
(6)
(7) Strongly Agree

8. The video appeals to my emotions.
Strongly Disagree
(1) (2)
(3)
(4)
(5)
(6)
(7) Strongly Agree 
Appendix B

Age:

\section{Part 1. Answer the following questions regarding your perceptions of vaping.}

1. How would you describe your level of consideration regarding vaping?

- I currently vape

- I have looked into vaping

- I have thought about vaping

- I have no interest in vaping

2. Check all that apply in relation to your consideration of vaping online:

- I have purchased vaping related products online (i.e., an electronic nicotine delivery system, a cartridge for a vaping device, etc.)

- I have searched for vaping related products online

- I have watched videos focused on vaping online

I have searched for videos containing the use of vapes online

3. I am concerned about the safety of vaping.
Strongly Disagree
(1)
(2)
(3)
(4)
(5)
(6)
(7) Strongly Agree

4. I am considering quitting vaping.
Strongly Disagree
(1)
(2)
(3)
(4)
(5)
(6)
(7) Strongly Agree

5. If my friend told me they were going to start vaping, I would try to convince them not to.
Strongly Disagree
(1)
(2)
(3)
(4)
(5)
(6)
(7) Strongly Agree 
Answer the following questions regarding your awareness of the following campaigns.

6. Are you aware of the FDA's "Real Cost" campaign to inform about the harmful effects of JUUL and other electronic nicotine delivery systems?

- Yes

- No

7. Have you ever seen one of the "Real Cost" videos regarding

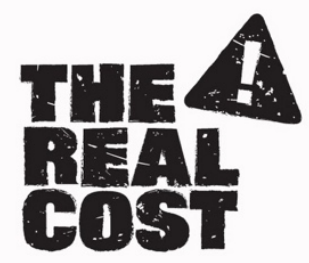
vaping? It would have contained the logo seen to the right.

- Yes

- No

8. If yes, where did you see it?

9. Do you recall any of the messages from the video?

- Yes

- No

10. If yes, what do you remember?

11. Are you aware of the Truth Initiative's "The Truth" campaign to inform about the harmful effects of JUUL and other electronic nicotine delivery systems?

- Yes

- No

12. Have you ever seen one of the "The Truth" videos regarding vaping? It would have contained the logo seen to the right.

- Yes

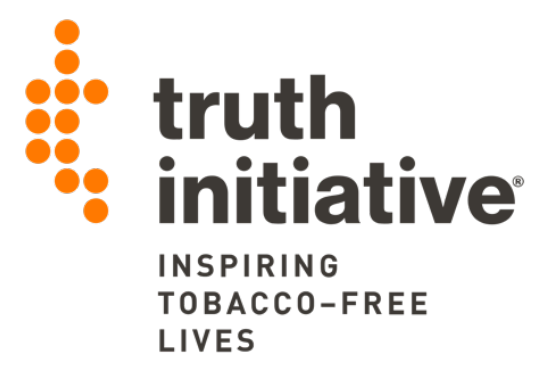


- No

13. If yes, where did you see it?

14. Do you recall any of the messages from the video?

- Yes

- No

15. If yes, what do you remember? 


\section{STOP:}

Do not flip this page until instructed to do so by the individual proctoring this session. 


\section{Part 2. Answer the following questions after watching the video.}

16. What are your overall thoughts after watching that video? List two or three reactions that you had. What stands out to you the most?

17. Have you seen this video before?

Yes No

18. If yes, where do you remember seeing the video:

19. If yes, how frequently do you see this video?

$\begin{array}{llll}1 & 2 & 3\end{array}$

Rarely Sometimes Often Very Often

Rank the video on a scale of 1 to 7 for how much you agree with each statement. 1

being Strongly Disagree, 4 being Neither Agree Nor Disagree, and 7 being Strongly

Agree.

20. The video had strong, believable information and is credible (credibility refers to the amount of these appeals used: Appeals to authority [person or organization], the person or organization is seen as trustworthy or reliable, it is objective, it appeals to expertise/the information comes from an expert).
Strongly Disagree
(1)
(2)
(3)
(4)
(5)
(6)
(7) Strongly Agree 
21. The video made a good argument.

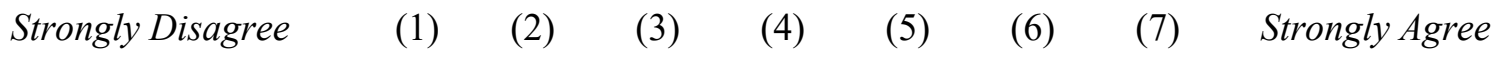

22. The video was rational.

Strongly Disagree $\quad$ (1) (2) (3) (4) (5) (6) (7) Strongly Agree

23. The video made me think.

Strongly Disagree $\quad$ (1) (2) (3) (4) (5) (6) $\quad$ (6)

24. The video was entertaining.
Strongly Disagree
(1) (2)
(3)
(4)
(5)
(6)
(7) Strongly Agree

25. The video was visually engaging (the look of it captures and holds my attention).
Strongly Disagree
(1) (2)
(3)
(4) (5)
(6)
(7) Strongly Agree

26. The video primarily uses visual representations to convey its message.
Strongly Disagree
(1)
(2)
(3)
(4)
(5)
(6)
(7) Strongly Agree

27. The video appeals to my emotions.
Strongly Disagree
(1) (2)
(3)
(4)
(5)
(6)
(7) Strongly Agree

28. Overall, I enjoyed watching the video.
Strongly Disagree
(1)
(2)
(3)
(4)
(5)
(6)
(7) Strongly Agree

Answer the following questions regarding your perceptions of vaping.

29. I am concerned about the safety of vaping.
Strongly Disagree
(1)
(2)
(3)
(4)
(5)
(6)
(7) Strongly Agree

30. I am considering quitting vaping.
Strongly Disagree
(1) (2)
(3)
(4)
(5)
(6)
(7) Strongly Agree

31. If my friend told me they were going to start vaping, I would try to convince them not to.
Strongly Disagree
(1) (2)
(3)
(4)
(5)
(6)
(7) Strongly Agree 


\section{Appendix C}

\section{The Real Cost Videos}

https://www.youtube.com/watch?v=3pXs2sipKy4\&feature=youtu.be https://www.youtube.com/watch?v=iKF5gZGOCZc\&feature=youtu.be https://www.youtube.com/watch?v=b6-QRkhpkBE https://www.youtube.com/watch? $\mathrm{v}=\mathrm{xn}$ yRhR hTw\&feature=youtu.be

\section{The Truth Initiative}

https://www.youtube.com/watch?v=Am_2u7wdJrA

https://www.youtube.com/watch?v=FhyoJNYvX7c\&feature=youtu.be https://www.youtube.com/watch?v=2bpf6tjj3A4\&feature=youtu.be https://www.youtube.com/watch?v=4ikOjZ qhCo\&feature=youtu.be 


\section{BIBLIOGRAPHY}

Anderson, M., \& Jiang, J. (2020, August 14). Teens, Social Media \&amp; Technology 2018. Retrieved October 31, 2020, from https://www.pewresearch.org/internet/2018/05/31/teens-social-media-technology$2018 /$

Andrews, J. C., \& Durvasula, S. (1991). Suggestions for manipulating and measuring involvement in advertising message content. ACR North American Advances.

Anker, A. E., Feeley, T. H., McCracken, B., \& Lagoe, C. A. (2016). Measuring the effectiveness of mass-mediated health campaigns through meta-analysis. Journal of Health Communication, 21(4), 439-456. Chicago

Binet, L., \& Field, P. (2009). Empirical generalizations about advertising campaign success. Journal of Advertising Research, 49(2), 130-133.

Bitner, M. J., \& Obermiller, C. (1985). The elaboration likelihood model: Limitations and extensions in marketing. ACR North American Advances.

Centers for Disease Control and Prevention (2020). CDC COVID Data Tracker.

Retrieved October 09, 2020, from

https:/covid.cdc.gov/covid-data-

tracker/?CDC_AA_refVal=https $\% 3 \mathrm{~A} \% 2 \mathrm{~F} \% 2 \mathrm{Fwww} . c d c . g o v \% 2 \mathrm{Fcoronavirus} \% 2 \mathrm{~F}$

2019-ncov\%2Fcases-updates\%2Fcases-in-us.html

Centers for Disease Control. (2019, October 28). Outbreak of Lung Injury Associated with E Cigarette Use, or Vaping. Retrieved from https://www.cdc.gov/tobacco/basic_information/e-cigarettes/severe-lung disease.html. 
Centers for Disease Control and Prevention. (2020a, February 25). Outbreak of Lung Injury Associated with the Use of E-Cigarette, or Vaping, Products. Retrieved October 09, 2020, Retrieved from https://www.cdc.gov/tobacco/basic_information/e-cigarettes/severe-lungdisease.html

Centers for Disease Control and Prevention. (2020b, September 09). Youth and Tobacco Use. Retrieved October 31, 2020, from https://www.cdc.gov/tobacco/data_statistics/fact_sheets/youth_data/tobacco_use/in dex.htm

Center for Tobacco Products. (2019, September 24). The Real Cost Campaign. Retrieved from https://www.fda.gov/tobacco-products/public-health-education/real-cost campaign\#1.

Center for Tobacco Products. (2019, October 8). Youth Tobacco Use: Results from the National Youth Tobacco Survey. Retrieved from https://www.fda.gov/tobacco-products/youth- and-tobacco/youth-tobacco-useresults-national-youth-tobacco-survey.

Dobbinson, S. J., Wakefield, M. A., Jamsen, K. M., Herd, N. L., Spittal, M. J., Lipscomb, J. E., \& Hill, D. J. (2008). Weekend sun protection and sunburn in Australia: trends (1987-2002) and association with SunSmart television advertising. American Journal of Preventive Medicine, 34(2), 94-101.

Dunbar, N. E., Connelly, S., Jensen, M. L., Adame, B. J., Rozzell, B., Griffith, J. A., \& Dan O'Hair, H. (2014). Fear appeals, message processing cues, and credibility in 
the websites of violent, ideological, and nonideological groups. Journal of Computer-Mediated Communication, 19(4), 871-889.

Farzal, Z., Perry, M. F., Yarbrough, W. G., \& Kimple, A. J. (2019). The adolescent vaping epidemic in the United States-How it happened and where we go from here. JAMA, Otolaryngology-Head \& Neck Surgery, 145(10), 885-886.

Flynn, B. S., Worden, J. K., Bunn, J. Y., Connolly, S. W., \& Dorwaldt, A. L. (2011). Evaluation of smoking prevention television messages based on the elaboration likelihood model. Health Education Research, 26(6), 976-987. https://academic.oup.com/her/article/26/6/976/595819

Gaiha, S. M., Cheng, J., \& Halpern-Felsher, B. (2020). Association between youth smoking, electronic cigarette use, and COVID-19. Journal of Adolescent Health, 67(4), 519-523.

Gagne, L. (2008). The 2005 British Columbia smoking cessation mass media campaign and short-term changes in smokers attitudes. Journal of Health Communication, 13(2), 125-148.

Hair, E. C., Cantrell, J., Pitzer, L., Bennett, M. A., Romberg, A. R., Xiao, H., ... \& Vallone, D. (2018). Estimating the pathways of an antitobacco campaign. Journal of Adolescent Health, 63(4), 401-406.

Jayaram, D., Manrai, A. K., \& Manrai, L. A. (2015). Effective use of marketing technology in Eastern Europe: Web analytics, social media, customer analytics, digital campaigns and mobile applications. Journal of Economics, Finance and Administrative Science, 20(39), 118-132. 
Jones, K., \& Salzman, G. A. (2020). The Vaping Epidemic in Adolescents. Missouri Medicine, 117(1), 56-58.

Langer, E. J., Blank, A., \& Chanowitz, B. (1978). The mindlessness of ostensibly thoughtful action: The role of" placebic" information in interpersonal interaction. Journal of Personality and Social Psychology, 36(6), 635.

Lim, Y. and Yap and Lau, T. 2011. The Effectiveness of Online Advertising in Purchase Decision: Liking, Recall and Click. Australian Journal of Basic and Applied Sciences. 5 (9): pp. 1517-1524.

MacKenzie, S. B., Lutz, R. J., \& Belch, G. E. (1986). The role of attitude toward the ad as a mediator of advertising effectiveness: A test of competing explanations. Journal of Marketing Research, 23(2), 130-143.

Martín, S. S., Camarero, C., \& José, R. S. (2011). Does involvement matter in online shopping satisfaction and trust?..Psychology \& Marketing, 28(2), 145-167.

Marynak, K., Gentzke, A., Wang, T. W., Neff, L., \& King, B. A. (2018). Exposure to electronic cigarette advertising among middle and high school students_-United States, 2014-2016. Morbidity and Mortality Weekly Report, 67(10), 294.

National Cancer Institute. (n.d.). NCI Dictionary of Cancer Terms. Retrieved from https://www.cancer.gov/publications/dictionaries/cancer-terms/def/electronic cigarette.

Palmgreen, P., \& Donohew, L. (2006). Effective mass media strategies for drug abuse prevention campaigns. In Handbook of Drug Abuse Prevention (pp. 27-43). Springer, Boston, MA. 
Palmgreen, P., Donohew, L., Lorch, E. P., Hoyle, R. H., \& Stephenson, M. T. (2001).

Television campaigns and adolescent marijuana use: tests of sensation seeking targeting. American Journal of Public Health, 91(2), 292.

Peetz-Schou, M. (1997). How to measure consumer awareness of mass-media campaigns for public health purposes. Patient Education and Counseling, 30(1), 53-59.

Chicago

Petty, R. E., \& Cacioppo, J. T. (1986). The elaboration likelihood model of persuasion. In Communication and Persuasion (pp. 1-24). Springer, New York, NY.

Reynolds, R. A., \& Burgoon, M. (1983). Belief processing, reasoning, and evidence. In R. Bostrom (Ed.), Communication Yearbook (Vol. 7, pp. 83-104). Beverly Hills, CA: Sage.

Rice, R. E., \& Atkin, C. K. (Eds.). (2012). Public communication campaigns. SAGE publications.

Robinson, M. N., Tansil, K. A., Elder, R. W., Soler, R. E., Labre, M. P., Mercer, S. L., ... \& Sokler, L. A. (2014). Mass media health communication campaigns combined with health-related product distribution: a community guide systematic review. American Journal of Preventive Medicine, 47(3), 360-371.

Santiago, S., Mahoney, C., Murray Jr, M. P., \& Benoza, G. (2019). “The Real Cost”: reaching at risk youth in a fragmented media environment. American Journal of Preventive Medicine, 56(2), S49-S56.

Selekman, J. (2019). Vaping: It's All a Smokescreen. Pediatric Nursing, 45(1). 
Singh, T., Agaku, I. T., Arrazola, R. A., Marynak, K. L., Neff, L. J., Rolle, I. T., \& King, B. A. (2016). Exposure to advertisements and electronic cigarette use among US middle and high school students. Pediatrics, 137(5).

Teng, S., Khong, K. W., \& Goh, W. W. (2014). Conceptualizing persuasive messages using ELM in social media. Journal of Internet Commerce, 13(1), 65-87.

Wootan, M. G., Reger-Nash, B., Booth-Butterfield, S., \& Cooper, L. (2005). The cost effectiveness of $1 \%$ or less media campaigns promoting low-fat milk consumption. Preventing Chronic Disease, 2(4), A05. 